\title{
Health education and health promotion
}

\author{
Raanan Gillon Imperial College and King's College, London University
}

What possible relevance, it might be asked, does health education have to a journal of medical ethics? And insofar as it is relevant what possible criticism could anyone make of this obviously admirable enterprise?

The first question is simply answered - health education is widely considered an integral part of medical practice and any ethical issues which it raises in this context are an appropriate substrate for medicomoral analysis. As for the second, Irma Kurtz in this issue and Gill Williams, in a previous issue (1), raise some doubts.

One theme in Irma Kurtz's critique is that the search for health has been incorporated into a contemporary religion of self-centredness and that by pandering to it the medical profession, at the head of a string of other health educators, have become the high priests of this 'paltry faith', promoting an excessive concern for bodily health and co-operating with a contemporary tendency in which 'the individual is no longer a member of a bigger community but a holy solipsist at the centre of his own universe'.

Her second major criticism is that the health educators 'relieve the individual of responsibility for himself which means they must blame the social order ... The poor fools who smoke, for example, are victims of a selfish society that refuses to outlaw tobacco. The poor girls who have teenaged pregnancies are paradoxically victims of a society that allows them contraceptives. Overweight is not the product of gluttony but of a failure of the glands or of mother's love. Suicide is not the result of existential despair but of divorce. The new puritan would deprive people of the privilege of taking responsibility for themselves ... would restrict freedom because to his way of thinking the free man will take liberties.'

Gill Williams focuses her concern on 'health promotion', contrasting it unfavourably with health education of which she approves and of which two central goals are 'rational decision-making and personal autonomy'. Health promotion by contrast involves, at least according to one of its advocates as cited by Ms Williams, 'the hard sell', and in this respect is no different from any other form of selling, whether of cigarettes, low fat spreads or the latest fashion. 'Promotion is about convincing other people that they need, or ought to have, what the salesman or promoter wants them to have'. Just as various protective questions are appropriate in the context of the commercial 'hard sell', so, suggests Ms Williams, $\vec{\omega}$ they are appropriate in the context of the health hard o sell. What precisely is on offer? Is it necessary/do I really want it? Does it work/do what is claimed of it? $\vec{z}$ Might it do harm/could I be worse off? And what's in it for the salesman? On Ms Williams's assessment $\stackrel{5}{S}$ health promotion does not always survive such questioning unscathed.

Thus, so far as what precisely is on offer goes, 'what those who seek to "promote health" must face up to is the need to provide evidence that there is a proven link between means and ends. But to many there is a . . . "credibility gap" between health and the stress of giving up cigarettes, the aches and pains of jogging, or the chore and tension of feeling for breast lumps'. And she adds 'There is no convincing evidence for example that finding a breast lump at an earlier stage necessarily increases the chance of cure; it may do so - in some cases - but there will be many others who will have to live with the fear of death for a longer time as a result of such promotion. The subtleties and complexities of decision-making for women in risk groups are beyond the scope of health promotion, and yet selfexamination is claimed to be a "high priority" [in South Australia]'.

Whether whatever behaviour change recommended $\frac{D}{O}$ by health promotion is necessary or desired by the recipient is again often a question of personal $\tilde{N}$ assessment, but even if the end to which it is claimed to $N$ be a means is desired, there remain the third and fourth $\mathrm{N}_{\mathrm{N}}$ questions: does the means actually work to produce the $\underset{\sigma}{\sigma}$ desired end and if so, at what risk of making things worse overall than they were before? Evidence of $\stackrel{0}{=}$ efficacy is at best probabilistic and is in any case often $\mathscr{\complement}$ conflicting. Moreover there are often harms involved. The long-term anxiety, for example, of knowing that they have a breast lump or a positive cervical smear or $\mathbb{D}$ high blood pressure may for some people outweigh the $\frac{O}{\mathbb{D}}$ reduction in risk of premature death which they may or may not gain from such knowledge.

Finally the question 'what's in it for the salesman?' is of an important one for both the recipient and for the provider of the health 'hard sell', and Ms Williams suggests that there is little evidence to counter her 
impression that often it is the 'salesmen' of health promotion who 'appear to be deriving more benefit from the enterprise than are the clients . . .

In a response to Ms Williams, (who teaches health education at London University), $\mathrm{Dr}$ Andrew Tannahill, a community physician with a special interest in health education, puts up a spirited defence (2) of what he sees as health promotion at its best, understood as an umbrella term covering the overlapping fields of health education, prevention and attempts to protect the public health through 'social engineering' (as for example through legislative or fiscal measures or through 'institutional policies'). Such health promotion, argues Dr Tannahill, can combine the best in terms of theory and practice from a wide range of expert groups including educationists, behavioural scientists and medical people as well as non-professionals including the communities concerned. Health promotion thus construed offers, Dr Tannahill argues, a new focus for the health services in response to such facts as: 1) that many contemporary health problems are preventable by modification of life-style; 2 ) that modern technology is a 'mixed blessing' bringing risks to health as well as benefits; 3) that modern medical technology 'is in a phase of diminishing returns'; 4) that non-medical factors including better nutrition, living conditions and public health measures, have contributed more to health and longevity than medical measures; 5) that doctors can causè disease as well as curè it, and 6) that there is an increasing public concern to attain a better quality of life while at the same time demystifying medicine and demedicalising the attainment of health.

None of that however is really to answer the worries expressed by Ms Williams including those about the manipulation involved in hard sell techniques, and about the need for good evidence concerning the harms and benefits and their probabilities on which to base the advice contained in any health promotion campaign.

There are at least three pairs of conflicting values which may be seen to underlie concern about health promotion. First there is the tension familiar in ordinary medical practice between doing what one believes to be best for a particular patient and respecting his or her autonomy even if such respect seems to result in what the health professional believes to be suboptimal results. Health promotion when it uses the techniques of the commercial hard sell surely tends to assume that the promoter's view of the optimal result should prevail whether or not the individual recipient believes that it is the best option for himself or herself. The techniques of the hard sell simply do not encourage the sort of autonomous assessment that, as Gill Williams puts it, is the aim of true education.

The second tension is between respect for the autonomy of the individual and concern for the interests of society in general. Now it might be argued that such a concern for the community over the individual meets Irma Kurtz's worries about the excessively individualistic cult of health which she decries. Even if this were so, it would surely be important to make it clear when the health promotion message is in the interests of the community as a whole rather than the individual recipient because this would mark a distinct change in emphasis from the normal medical interaction and recipients and doctors alike need to be aware of this. In any case the concern indicated by Irma Kurtz is clearly itself an autonomyrespecting concern, even though it seeks to remind the individual that there is more than self and more than body to be concerned about. Thus the human privilege of taking responsibility for oneself, which includes as she puts it 'the right to make mistakes', is a crucial value in Kurtz's paper. (In this context Dr Tannahill's remark that health promotion should give 'due recognition' to what he calls 'the illusory nature of free rational choice' (2) may strike a certain chill.)

The third tension, not reflected in these papers, but discussed at a conference on ethical issues in preventive medicine (3), and a familiar theme in the context of allocation of scarce medical resources, is how best to distribute the goods of health promotion. Should it be a question simply of maximising the anticipated improvement of health, or ought such improvement to be distributed in ways that, for example, favour the most disadvantaged?

While the concern for respect for autonomy emphasised by Kurtz and Williams is clearly an important ethical issue in health promotion it is also important to recall that the hard sell methods of contemporary health promotion are part of a response to exceedingly well-funded commercial hard sell methods which democratic societies have taken to their bosom and nurtured. All around us, on television, in newspapers and on public hoardings hard sell methods entice us, for example, to drink alcohol and smoke cigarettes. While it might be argued that medicine and the health care professions should none the less themselves avoid stooping to these methods, the counterarguments are obviously powerful (including that implied in Rowland Hill's remark about not letting the devil have all the best tunes). Whatever we decide, Kurtz and Williams alert us to some of the important medico-moral issues that the apparently uncontroversial activities of health promotion evoke. And if health promotion is to use the methods of modern commerce then recipients, health promoters and governments alike would surely be wise to heed the critical questions Ms Williams suggests are relevant to the use of any such hard sell activities.

\section{References}

(1) Williams G. Health promotion - caring concern or slick salesmanship? Fournal of medical ethics 1984; 10: 191-195.

(2) Tannahill A. Health promotion - caring concern. Fournal of medical ethics 1984; 10: 196-198.

(3) Doxiadis $\mathrm{S}$, ed. Ethical issues in preventive medicine. Dordrecht/Boston/Lancaster: Martinus Nijhoff, 1985: CF 25-31. 